\title{
SOME CIRCULATORY RESPONSES TO VALSALVA'S MANOEUVRE IN PATIENTS WITH POLYNEURITIS AND SPINAL CORD DISEASE
}

\author{
W. E. WATSON \\ From the Department of Neurology, Churchill Hospital, Oxford
}

The response of the arterial blood pressure and of the capacity vessels, or veins, of the hand to Valsalva's manoeuvre was investigated in two patients with ccmplete traumatic lesions of the spinal cord in the cervical region and in two patients with severe acute polyneuritis.

\section{METHODS}

Arterial blood pressure was recorded through a Cournand needle inserted into the brachial artery. Distensibility of the capacity vessels was measured by comparing the increase in hand volume resulting from intermittent obstruction of the venous return from the hand with the simultaneous rise in venous pressure of the hand.

Hand volume changes were measured with a waterfilled plethysmograph of $5 \cdot 16$ litres capacity. The water was stirred continuously and its temperature maintained at $34 \pm 0.5^{\circ} \mathrm{C}$. The patient lay supine with the hand in the plethysmograph at the level of the manubriosternal joint. The water within the plethysmograph exerted a hydrostatic pressure of 8 to $11 \mathrm{~cm}$. water upon the dorsum of the hand. Hand volume changes were derived from pressure changes of the air contained within the turret of the plethysmograph. Ambient temperature was constant throughout each investigation, within the range 22 to $25^{\circ} \mathrm{C}$.

Venous pressure was measured through a nylon catheter of $0.8 \mathrm{~mm}$. internal diameter introduced percutaneously on the dorsal or radial aspect of the radiocarpal joint and directed peripherally. The catheter was made to negotiate at least one venous valve and the end of the catheter lay about $5 \mathrm{~cm}$. distal to the site at which the vein was punctured. Care was taken that the end of the catheter was not wedged in a venous tributary. The catheter was periodically flushed with $0 \cdot 2 \mathrm{ml}$. of a solution of saline containing $0.01 \mathrm{mg} . / \mathrm{ml}$. of heparin.

All pressures were measured with capacitance transducers (Southern Instruments), and records were obtained with a four-channel direct-writing pen unit. The pens were $16 \mathrm{~cm}$. long, worked in an arc of $4 \mathrm{~cm}$., and had a peak to peak response time of 0.07 second. The paper speed usually used was $5 \mathrm{~mm}$./second.

An occluding pneumatic cuff was placed round the wrist immediately proximal to the plethysmograph and intermittently inflated to $40 \mathrm{~mm}$. $\mathrm{Hg}$ for 10 to 20 seconds. During each period of venous occlusion the hand volume and venous pressure were continuously recorded.
EXPRESSION OF RESULTS The increase in hand volume was expressed graphically against the increase in hand venous pressure. The measured increase in hand venous pressure included the transmitted rise in pressure within the plethysmograph as a consequence of increase in hand volume. The true rise in venous pressure was therefore derived by subtracting the rise in pressure within the plethysmograph from the total rise in venous pressure. As the rise of pressure within the plethysmograph during an episode of occlusion of venous return never exceeded $7 \%$ of the total rise in venous pressure, this correction was small.

The transmural hand venous pressure, or venous distending pressure, was derived by subtracting the hydrostatic pressure, due to the column of water within the plethysmograph above the back of the hand, from the venous pressure. This hydrostatic pressure always exceeded the resting hand venous pressure. As the hydrostatic pressure was directly transmitted to both hand tissues and hand veins the venous distending pressure was near zero between episodes of venous occlusion, indicating that the veins were collapsed (Ryder, Molle, and Ferris, 1944).

PROCEDURE After the apparatus had been set up, no measurement of capacity vessel distensibility was made for about 30 minutes. Twenty consecutive records were then analysed. The tracheal pressure of the patient was then increased to $40 \mathrm{~mm}$. $\mathrm{Hg}$ for 20 seconds. During this time, and for the following five minutes, arterial blood pressure was continuously recorded and frequent measurements were made of the distensibility of the capacity vessels.

Finally, all of the patients were given noradrenalin by intravenous infusion at $2 \mu \mathrm{g}$./minute for six minutes to determine whether the capacity vessels could alter their distensibility in response to direct stimulation.

SUBJECTS Each of the four patients had severe respiratory weakness or paralysis, and received intermittent positive pressure respiration from a Radcliffe respiration pump (Russell, Schuster, Smith, and Spalding, 1956) through a cuffed tracheotomy tube (Spalding and Smith, 1956) which provided an airtight seal in the trachea. All patients had clinically and radiologically normal lungs at the time of investigation.

Because of respiratory weakness, and because the patients had tracheotomies, they were unable to perform 
Valsalva's manoeuvre by straining against a closed glottis. A source of pressure was therefore applied to the trachea and maintained at the desired level for 20 seconds. As these patients were unable to raise their intra-abdominal pressure by straining when the intrathoracic pressure was raised, it is probable that the stress cast upon the circulation was greater than normal, as blood could probably also be dammed back within the abdomen.

The response of the arterial blood pressure to Valsalva's manoeuvre was also investigated in three normal healthy subjects.

\section{RESULTS}

Fig. 1 is a record of the response of the arterial blood pressure to Valsalva's manoeuvre in a normal subject. Initially the arterial blood pressure was transiently raised as the elevated intrathoracic pressure was transmitted directly to the mediastinal arteries. A progressive fall of diastolic arterial blood pressure and of pulse pressure followed, and continued for about five to 10 seconds. The diastolic blood pressure then began to rise and the pulse pressure increased. When the intrathoracic pressure fell at the end of the manoeuvre a sharp transient fall in blood pressure occurred, as the reduction of intrathoracic pressure was transmitted to the mediastinal arteries. Finally, the diastolic pressure and pulse pressure increased markedly, both exceeding their previous resting values. During this characteristic 'overshoot' of the arterial blood pressure bradycardia occurred. The arterial blood pressure returned to normal within 30 seconds of the end of the Valsalva manoeuvre.

Fig. $2 a$ is a record of the arterial blood pressure obtained during Valsalva's manoeuvre in a patient with severe acute polyneuritis. While the intrathoracic pressure remained high, diastolic blood pressure and pulse pressure fell progressively. When the manoeuvre was concluded the diastolic pressure and pulse pressure returned slowly to their initial values. No 'overshoot' of the arterial blood pressure was seen and no bradycardia occurred. Fig. $2 \mathrm{~b}$ is a record similarly obtained from a patient
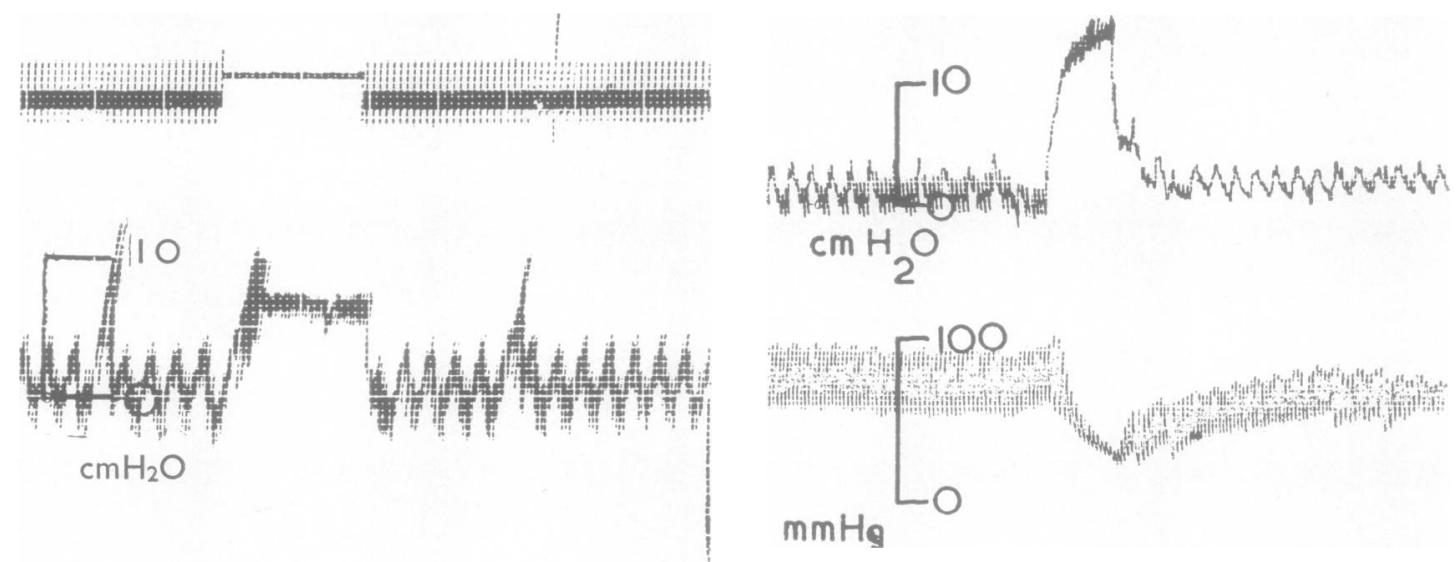

FIG. $2 \mathrm{a}$
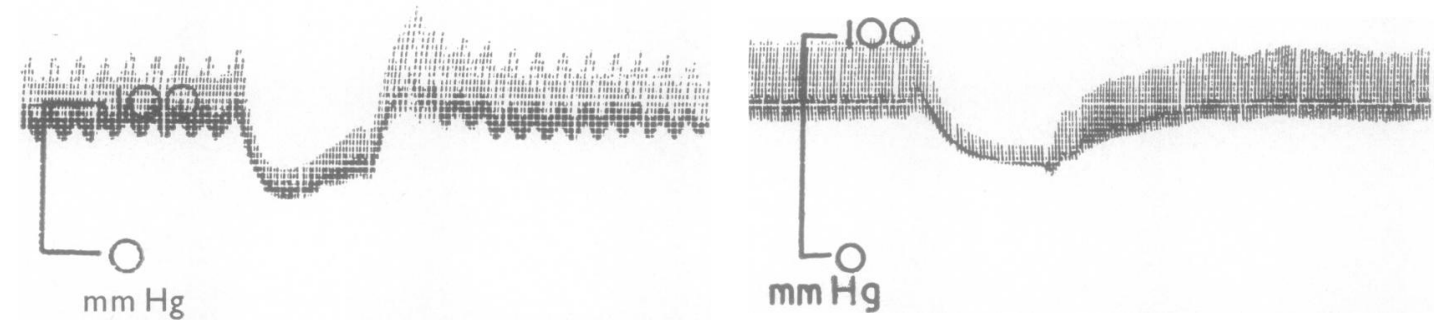

FIG. 1

FIG. $2 b$

FIG. 1. Record of the arterial blood pressure response to Valsalva's manoeuvre performed by a normal subject. Upper trace intrathoracic pressure, lower trace, arterial blood pressure, time in seconds.

FIG. 2a. Response of arterial blood pressure to Valsalva's manoeuvre in a patient with acute severe polyneuritis. Upper trace, intrathoracic pressure, lower trace, arterial blood pressure.

FIG. 2b. Response of arterial blood pressure to Valsalva's manoeuvre in a patient with a complete traumatic lesion of the cervical spinal cord. 

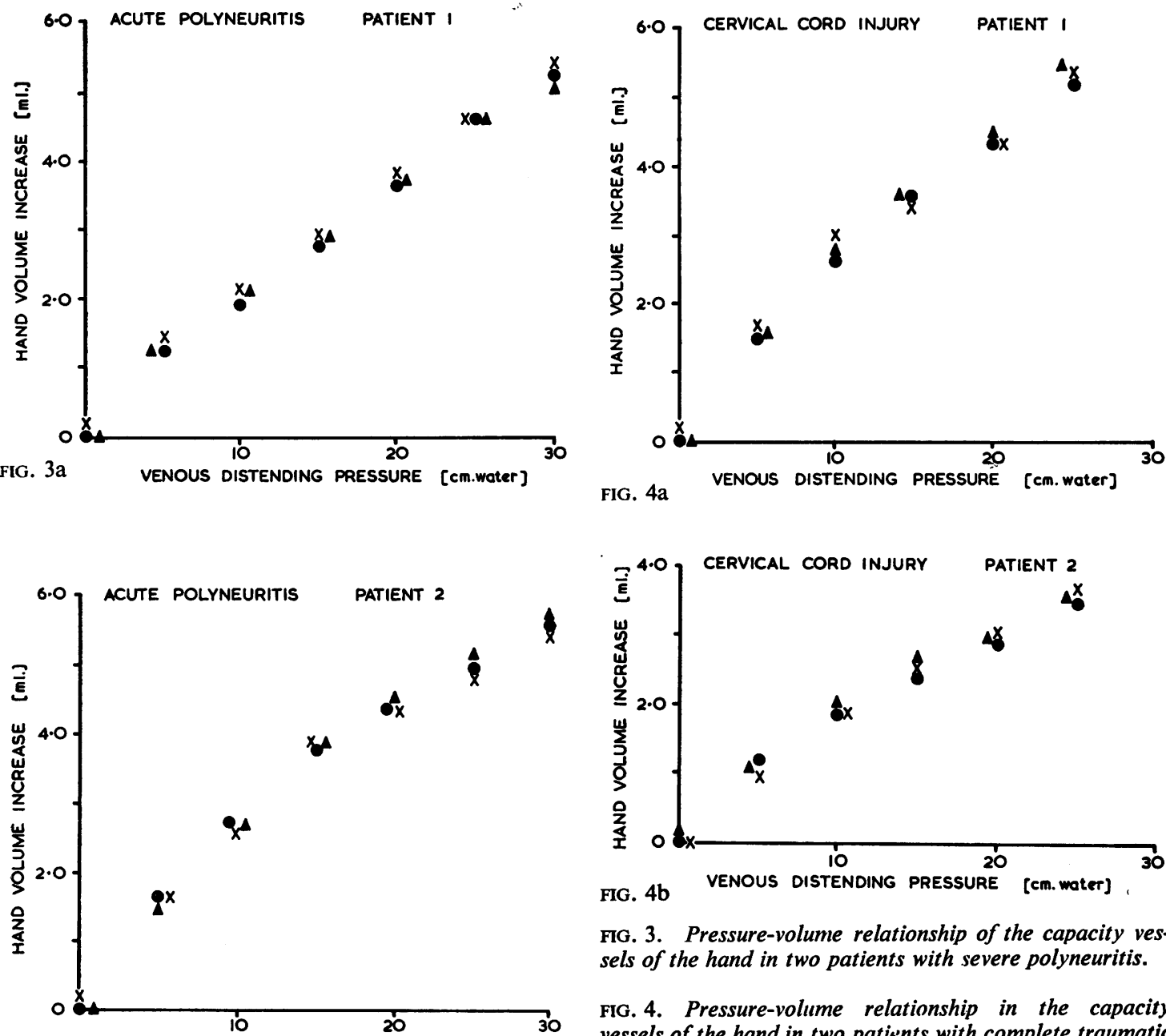

FIG. $3 \mathrm{~b}$ VENOUS DISTENDING PRESSURE [cm.water]

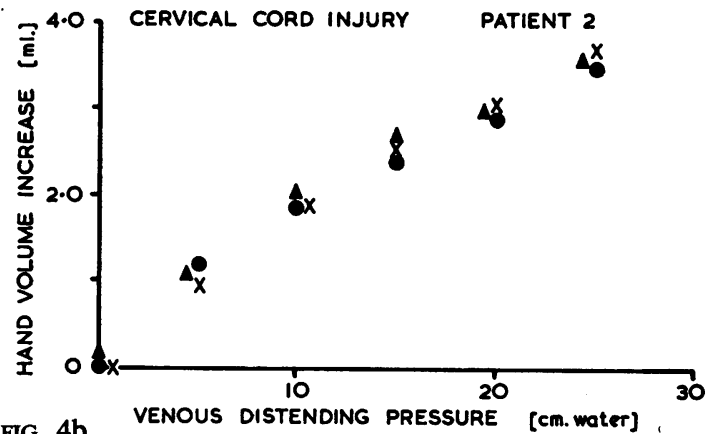

FIG. 3. Pressure-volume relationship of the capacity vessels of the hand in two patients with severe polyneuritis.

FIG. 4. Pressure-volume relationship in the capacity vessels of the hand in two patients with complete traumatic lesions in the cervical spinal cord.

with a complete lesion of the spinal cord at the second cervical segment.

Figs. $3 \mathrm{a}$ and $3 \mathrm{~b}$ show the distensibility of the capacity vessels of the hand of the two patients with severe polyneuritis. The solid dots represent values obtained before the Valsalva manoeuvre, and each point shown represents a mean derived from 20 episodes of occlusion of the venous return. The crosses represent values obtained during the Valsalva manoeuvre, and the raised hand venous pressure found during the Valsalva manoeuvre is due in part to the damming back of blood within the systemic veins as a result of raised intrathoracic pressure and in part to local occlusion of venous return with the pneumatic cuff. The values shown are mean values derived from two or three performances of the

Valsalva manoeuvre. The triangles represent values obtained after the Valsalva manoeuvre was completed: each point shown is a mean value derived from 20 consecutive episodes of venous occlusion starting immediately after the end of the Valsalva manoeuvre. No change in the vascular distensibility of the hand was found as a result of raising the intrathoracic pressure. Similar results obtained on two patients with complete lesions of the cervical part of the spinal cord are shown in Figs. $4 a$ and $4 b$.

Figs. $5 \mathrm{a}$ to $5 \mathrm{~d}$ demonstrate the reduction in distensibility of the capacity vessels of the hand which occurred when these patients were given an intravenous infusion of noradrenalin at $2 \mu \mathrm{g}$./minute. The triangles represent values obtained after 


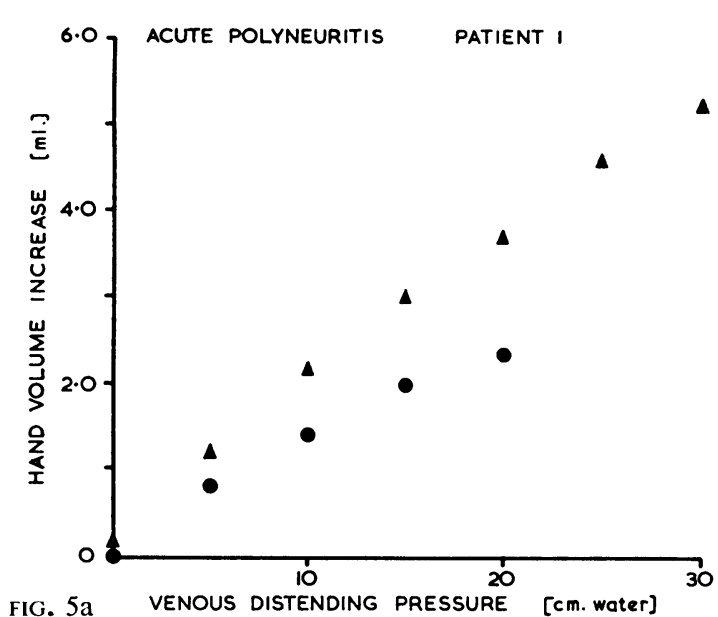

FIG. 5a VENOUS DISTENDING PRESSURE [cm. water]

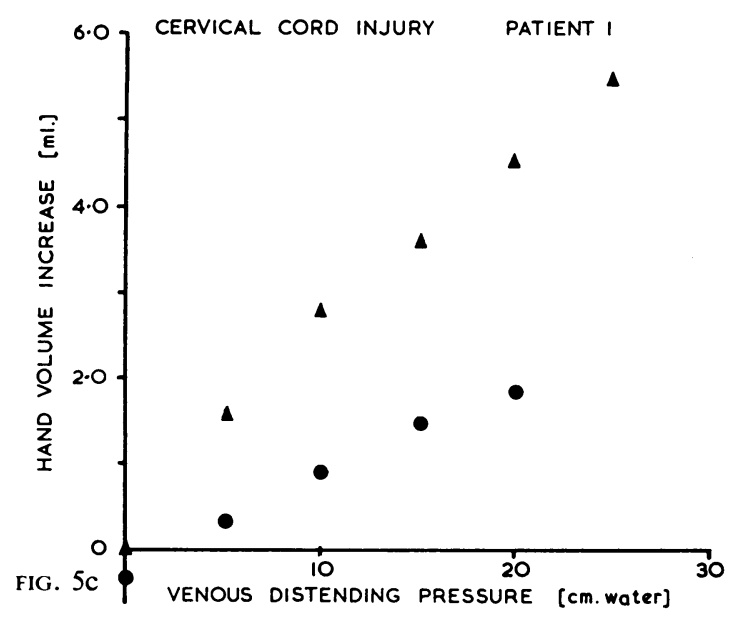

Valsalva's manoeuvre immediately before noradrenaline, and the solid dots those obtained during noradrenaline infusion.

\section{DISCUSSION}

The technique used in this investigation for measuring the distensibility of the capacity vessels is similar to that employed by Sharpey-Schafer (1961) for determining the vascular pressure-volume relationship of the forearm. It is related to the plethysmograph methods of measuring venous distensibility in vivo (Clark, 1933; Kidd and Lyons, 1958; Glover, Greenfield, Kidd, and Whelan, 1958; Eckstein and Horsley, 1960). The vessels investigated are the low pressure capacity vessels, which consist almost entirely of veins (Litter and Wood,
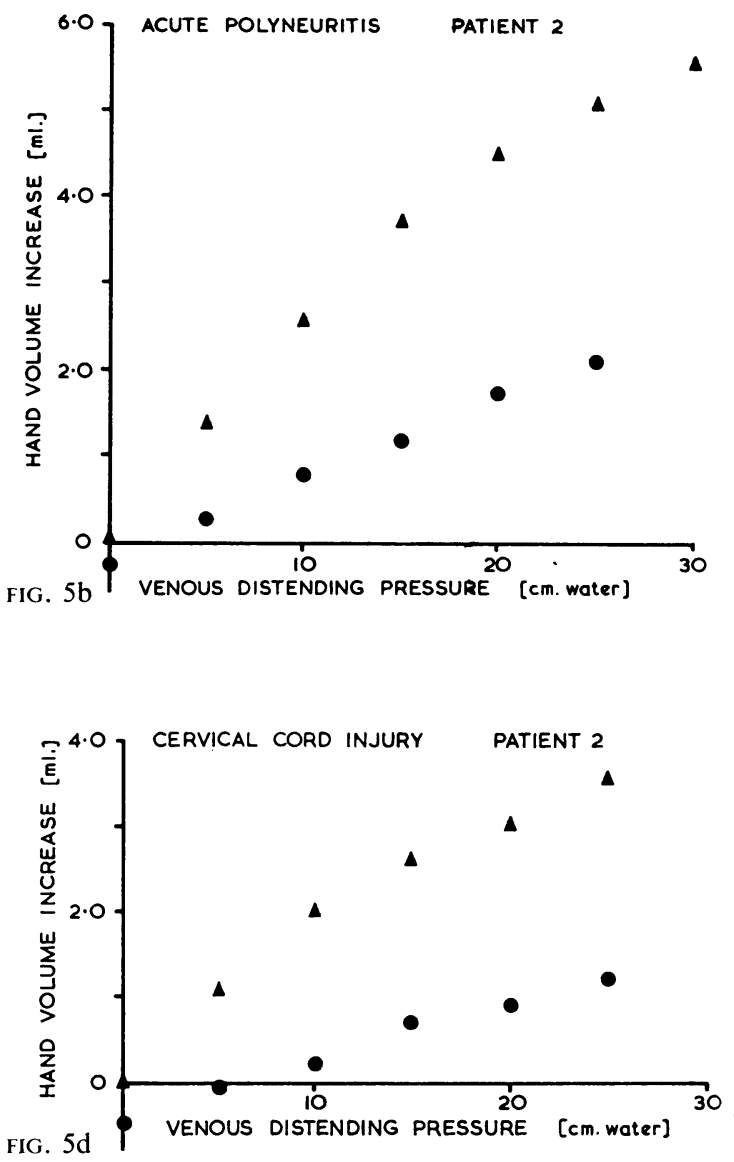

FIG. 5. A reduction in distensibility of the capacity vessels of the hand in all four patients when noradrenaline was infused intravenously.

1954). These vessels were collapsed by the imposed hydrostatic pressure of the fluid within the plethysmograph, so that a reasonably constant baseline hand venous volume was assured (Clark, 1933).

The abrupt raising of the mean intrathoracic pressure which occurs during Valsalva's manoeuvre (Valsalva, 1707) causes a marked fall in the filling pressure of the right side of the heart (Lee, Matthews, and Sharpey-Schafer, 1954). Blood pressure changes and alteration of blood flow in the forearm in response to this have been extensively investigated in normal subjects (Sharpey-Schafer, 1953, 1955) and in patients with chronic disease of the afferent nervous system (Sharpey-Schafer, 1956). The capacity vessels of the hand in normal subjects become constricted during Valsalva's manoeuvre (Watson, in preparation), and this constriction is probably 
partially responsible for the characteristic 'overshoot' of the arterial blood pressure.

The response of the arterial blood pressure to elevation of the intrathoracic pressure differed in patients with severe polyneuritis or complete lesions of the cervical part of the spinal cord from the response found in normal subjects. No increase in pulse pressure occurred in the second half of the 20-second period for which the intrathoracic pressure was raised and no increase in diastolic pressure was found. When the intrathoracic pressure returned to normal, no secondary 'overshoot' of the diastolic blood pressure and pulse pressure was found, and there was no bradycardia. These abnormal responses of the arterial blood pressure were associated with absence of the normal reduction of distensibility of the capacity vessels, or veins, of the hand. As the distensibility of the veins is not reduced in these patients the amount of blood which is dammed back within the venous tree during the Valsalva manoeuvre is probably greater than in normal subjects. Similarly, when the Valsalva manoeuvre is concluded, it is probable that the excess blood is removed less rapidly from the veins than if the venous distensibility had undergone its normal reduction. It is therefore probable that in these patients the abnormal response of the arterial blood pressure to the Valsalva manoeuvre is due in part to the failure of the capacity vessels or veins of the systemic circulation to become less distensible when the intrathoracic pressure is raised.

The reduction of distensibility of the veins of the hand in response to the intravenous infusion of noradrenaline indicates that the vessels were capable of altering their distensibility in response to direct stimulation. The failure of these vessels to respond normally to elevation of the mean intrathoracic pressure is almost certainly a consequence of abnormality of their innervation.

\section{SUMMARY}

Arterial blood pressure and the distensibility of the capacity vessels of the hand were measured in two patients with severe polyneuritis and in two patients with complete lesions of the cervical part of the spinal cord. These patients showed an abnormal response of the arterial blood pressure to the Valsalva manoeuvre, and failed to show the normal reduction in hand venous distensibility in response to the Valsalva manoeuvre.

I am greatly indebted to Dr. W. Ritchie Russell, Dr. J. M. K. Spalding, and Dr. A. Crampton Smith for the opportunity to study patients under their care and for research facilities. Dr. E. Seelye helped in the presentation of the paper and the records were photographed by $\mathrm{Mr}$. Tugwell of the Radcliffe Infirmary. The investigation was supported by a grant from the National Fund for Research into Poliomyelitis and Other Crippling Diseases.

\section{REFERENCES}

Clark, J. H. (1933). Amer. J. Physiol., 105, 418.

Eckstein, J. W., and Horsley, A. W. (1960). J. Lab. clin. Med., 56, 847.

Glover, W. E., Greenfield, A. D. M., Kidd, B. S. L., and Whelan, R. F. (1958). J. Physiol. (Lond.), 140, 113.

Kidd, B. S. L., and Lyons, S. M. (1958). Ibid., 140, 122.

Lee, G. de J., Matthews, M. B., and Sharpey-Schafer, E. P. (1954) Brit. Heart J., 16, 311.

Litter, J., and Wood, J. E. (1954). J. clin. Invest., 33, 798.

Russell, W. R., Schuster, E., Smith, A. C., and Spalding, J. M. K (1956). Lancet, 1, 539.

Ryder, H. W., Molle, W. E., and Ferris, E. B. (1944). J. clin. Invest., 23, 333.

Sharpey-Schafer, E. P. (1953). J. Physiol. (Lond.), 122, 351.

(1955). Brit. med. J., 1, 693.

(1956). J. Physiol. (Lond.), 134, 1.

(1961). Oliver Sharpey Lectures. Royal College of Physicians, London.

Spalding, J. M. K., and Smith, A. C. (1956). Lancet, 2, 1247.

Valsalva, A. M. (1707). De Aure Humana Tractatus., p. 84. G. vande Water, Utrecht. 